\title{
Curricular Choice and Technical - Non-Technical Balance in Environmental Engineering Degree Programs
}

\section{Dr. Angela R. Bielefeldt, University of Colorado - Boulder}

Angela Bielefeldt is a professor at the University of Colorado Boulder in the Department of Civil, Environmental, and Architectural Engineering (CEAE). She serves as the ABET assessment coordinator for the department. Professor Bielefeldt is the faculty director of the Sustainable By Design Residential Academic Program, a living-learning community where interdisciplinary students learn about and practice sustainability. Bielefeldt is also a licensed P.E. Professor Bielefeldt's research interests in engineering education include service-learning, sustainable engineering, social responsibility, ethics, and diversity.

\section{Dr. Marissa H. Forbes, University of Colorado - Boulder}

Marissa H. Forbes is a research associate at the University of Colorado Boulder and lead editor of the TeachEngineering digital library. She previously taught middle school science and engineering and wrote K-12 STEM curricula while an NSF GK-12 graduate engineering fellow at CU. With a master's degree in civil engineering she went on to teach physics for the Denver School of Science and Technology (DSST), where she also created and taught a year-long, design-based DSST engineering course for seniors. Forbes earned her $\mathrm{PhD}$ in civil engineering, with an engineering education research focus.

\section{Dr. Jacquelyn F. Sullivan, University of Colorado - Boulder}

Jacquelyn Sullivan is founding co-director of the General Engineering Plus degree program in the University of Colorado Boulder's College of Engineering and Applied Science. She spearheaded design and launch of the Engineering GoldShirt Program to provide a unique access pathway to engineering for high potential, next tier students not admitted through the standard admissions process and the CU teach Engineering Program - creating a pathway to secondary math and science teacher licensure through engineering. Sullivan was conferred as an ASEE Fellow in 2011 and was awarded NAE's 2008 Gordon Prize for Innovation in Engineering and Technology Education. 


\title{
Curricular Choice and Technical - Non-Technical Balance in Environmental Engineering Degree Programs
}

\begin{abstract}
Self-determination theory indicates that choice is an important component of motivation and satisfaction. Further, calls for holistically trained engineers demand that students gain knowledge in humanities and social science topics. This research explored top-ranked environmental engineering bachelor's degree programs with regards to: (1) opportunities for students to make choices in their courses (such as free electives and technical electives); and (2) the balance of required technical and non-technical courses in the curriculum. These metrics were compared with chemical and civil engineering degrees, as well as mathematics, chemistry, and physics degrees. The curricular requirements were determined using the 2013-2014 online university catalogs, including counting and characterizing degree program credit hours as either technical coursework (engineering, math, and natural science), non-technical coursework, or free electives. Among the 19 environmental engineering degree programs explored in this study, free electives ranged from 0 to $22 \%$ of the curriculum, with a median of $0 \%$. The total amount of the curriculum that allowed any level of choice ranged from 14 to $80 \%$, with a median of $44 \%$. This shows a high degree of variability among top-rated environmental engineering programs in the amount of course choices that students can make. By comparison, the median for all engineering programs at top-ranked institutions was 3\% free electives and $40 \%$ any type of choice. The percentage of technical courses in the environmental engineering curricula ranged from 56 to $86 \%$, with a median of $78 \%$. The median across all engineering programs was very similar at $76 \%$ technical. The percentage of non-technical courses in the environmental engineering curricula ranged from 13 to $36 \%$, with a median of $20 \%$; similar to the median of $21 \%$ across all engineering programs. Degrees in math, chemistry, and physics had higher percentages of free electives (median 18-19\%) and total choice (65-81\%), and lower technical requirements (median 47-54\%), as compared to engineering degrees. The results demonstrate that environmental engineering students have comparatively less choice and curricular balance that peers in natural science and math. However, there are accredited and highly ranked environmental engineering programs that allow both choice and greater curricular balance. These programs serve as examples to others who may want to design programs that allow students to exercise their innate need for autonomy and also balance their educational experience.
\end{abstract}

\section{Introduction}

Self-determination theory indicates that human beings have an innate psychological need for autonomy, satisfied through choice. ${ }^{1,2}$ Choice is an important component of motivation and satisfaction, and a tool to be utilized in educational settings $1,2,12,13,14,15,16,17$ to nurture beneficial educational outcomes such as creativity, cognitive flexibility, self-esteem, increased engagement, higher quality learning, intrinsic motivation, self-regulation, and well-being. ${ }^{1,2}$ Previous studies have found that engineering programs are typically highly restrictive and present students with few opportunities to explore academically through course choice opportunities, presenting a hypothesized dissonance with students' psychological and developmental needs, and therefore an obstacle to participation in engineering programs. ${ }^{3,4}$ Across over 300 ABET Engineering Accreditation Commission (EAC)-accredited engineering programs, for example, engineering students were afforded a median of $2 \%$ of their undergraduate program as free electives, 
compared to a median of almost one-fourth of non-engineering students' degree programs. ${ }^{4}$ This same work also found that engineering programs nationwide were highly skewed towards technical content, a median of $78 \%$ of total degree coursework across 100 programs, ${ }^{4}$ despite ABET's requirement of only $62.5 \%$ technical content. ${ }^{5}$ The high technical content and minimal free elective opportunity curricular model combination also infers minimal opportunity for students to pursue a broad and balanced liberal engineering education.

Over a number of years teaching an introductory environmental engineering course ${ }^{19}$ for first year students, some students described their intent to leave engineering due to the restrictive curriculum and/or a desire for more balance between technical and non-technical courses. These thoughts were revealed in their reflective essays at the end of the semester. For example, one student described a desire for balance between technical and non-technical coursework:

Currently, I am unsure of whether or not I want to continue with the environmental engineering program and become an engineer. Prior to attending CU, I was convinced I was going to become an engineer and save the world... [but] I do not like how technical my course schedule is. As I learned when I did [the course plan] for [environmental engineering], there are relatively few slots open for humanities and social studies courses. I consider myself a very creative person, and enjoy thinking creatively, and it seems there is very little room for such thinking in the engineering program (at least until upper level courses).

Another student voiced similar concerns about the heavy technical focus, writing:

I have decidedly changed my major out of environmental engineering for the rest of my time at the University of Colorado. This isn't to say that many aspects of environmental engineering don't appeal to me. The overall ability an environmental engineer has to help various peoples and nations, I'm sure is incredibly rewarding...much more rewarding than any paycheck. But even so, based upon my current classes and the course plan in order to graduate with a degree, [the] amount of technical and computer training required for this degree is unappealing to me. ...I also enjoy the mathematical and scientific aspect of the degree, [but] I am the most interested in the aspect that "[environmental engineering] graduates have adequate understanding of the social, economic, political, and ethical context of environmental problems and solutions". Thus, from this semester and taking Intro to Environmental Engineering, I have learned that overall I am interested in the environmental aspect of the degree but not the engineering facet, which is why I have decided to change my major.

Two students described a strong interest in a non-engineering field and a desire for a dual major (one in journalism and the other in psychology), but were uncertain that the environmental engineering curriculum could accommodate their wider interests. One student wrote:

I wanted to travel, work with local peoples, and actually teach them about sustainable living, and not just in terms of water treatment but also in other areas such as better agriculture and waste management techniques.... Despite all of this however, I am still unsure whether or not environmental engineering is the right major for me. One of the biggest reasons for this is because I am not sure I would be happy doing the amount of math required in the engineering field. Also, after completing [the environmental engineering course plan] I realized that I got much more excited about the classes dealing 
with culture and the environment (i.e.: "people and the environment" and "global development") and it made me wonder whether or not environmental studies would fit me better. Additionally, I am currently enrolled in the journalism school and I was hoping that if I were to transfer into the engineering school, I could keep journalism as a second major. However, after studying my four-year course plan, I realized it would be nearly impossible to do both and still graduate on time. Moreover, I was really hoping I could go abroad at some point during my college career, but with the strict requirements of [environmental engineering] I came to the conclusion that studying abroad for credit would be a difficult thing to do. All in all, I enjoyed taking this class and I think environmental engineering for developing communities is something I would really enjoy doing in the future, however I am not convinced that I would be happy with the amount of math required for the degree or having to give up journalism and study abroad.

The other student with similar concerns wrote:

I feel that given my particular skill set (strong with science, love the environment, and am good working with/ mitigating with people) it is my duty to become an environmental engineer. I have always been passionate to figure out how things work, and environmental engineering is a way to use that passion to hopefully change the world someday. However, there are also things that I dislike about environmental engineering...the environmental engineering major [course requirements]...this is a problem for me because it would require much more schooling and less diversification of my course selection (which is a problem for me because I am also extremely fascinated with psychology and would hard pressed to choose one over the other)...I have my doubts over whether environmental engineering is the major I will stay with if my ambitions can better be satisfied elsewhere.

These four quotes were chosen from a larger number of examples from a fall 2009 course reflection assignment of environmental engineering students citing dissatisfaction with the minimal course choice and non-technical opportunities in the ABET EAC-accredited environmental engineering program at the University of Colorado Boulder (CU). It is uncertain the extent to which these concerns are limited to the particular environmental engineering curriculum at CU. Do environmental engineering degree programs around the U.S. generally allow students sufficient course choices and a sufficient balance of technical/non-technical coursework, or are other environmental engineering curricula similarly limited?

ABET EAC accreditation for all engineering degree programs requires 1-year of math and basic natural sciences, 1.5-years of engineering coursework, and a general education component (an unspecified quantity; in contrast to pre-EC2000 requirements for 0.5 -year of humanities and social sciences). ${ }^{5}$ Accreditation also requires demonstration that students have met 11 outcomes. These outcomes span technical and professional competencies. Outcome (h) seems to refer to non-technical competencies and the general education component, requiring "the broad education necessary to understand the impact of engineering solutions in a global, economic, environmental, and societal context." 5 (p. 3) The program-specific criteria for environmental engineering have additional restrictions, among the most restrictive of all specialty programs. This may be the result of the large number of societies which are responsible for the criteria, led by the American Academy of Environmental Engineers and Scientists and with seven cooperating societies. The program specific criteria outline 15 knowledge/skill areas, some with a high level of detail. For example, the specific types of chemistry knowledge are noted 
(stoichiometry, equilibrium, and kinetics). In total, the curriculum requirements description is 142 words. Contrast these requirements with chemical engineering where the requirements were set by a single lead society, articulate only eight areas, and are explained in 61 words. The civil engineering criteria are similarly restricted as the environmental, specifying 15 areas, but explained more concisely in 106 words.

Per an ABET program search (November 11, 2015), there are 67 accredited environmental engineering (EnvE) 4-year degree programs in the U.S. ${ }^{6}$ Based on the year first accredited, the number of accredited programs has been steadily rising since about 1990 . The majority of the programs accredited today were likely first accredited under the outcomes-based format of EC2000 rather than the previous more prescriptive requirements. The general characteristics of the 67 accredited programs are summarized in Table 1; in addition, 47 of the programs (70\%) are at public institutions and 20 are at private institutions. It is also important to note that some formerly accredited EnvE programs have ceased. For example, Stanford's EnvE program ceased ABET accreditation after June 2015. ${ }^{7}$ South Dakota School of Mines and Technology has an accredited Environmental Engineering degree but no longer offers the EnvE B.S. degree; EnvE is now just an emphasis within the civil engineering degree. ${ }^{8}$ Thus, it is important to keep in mind that the precise program situation can change rapidly.

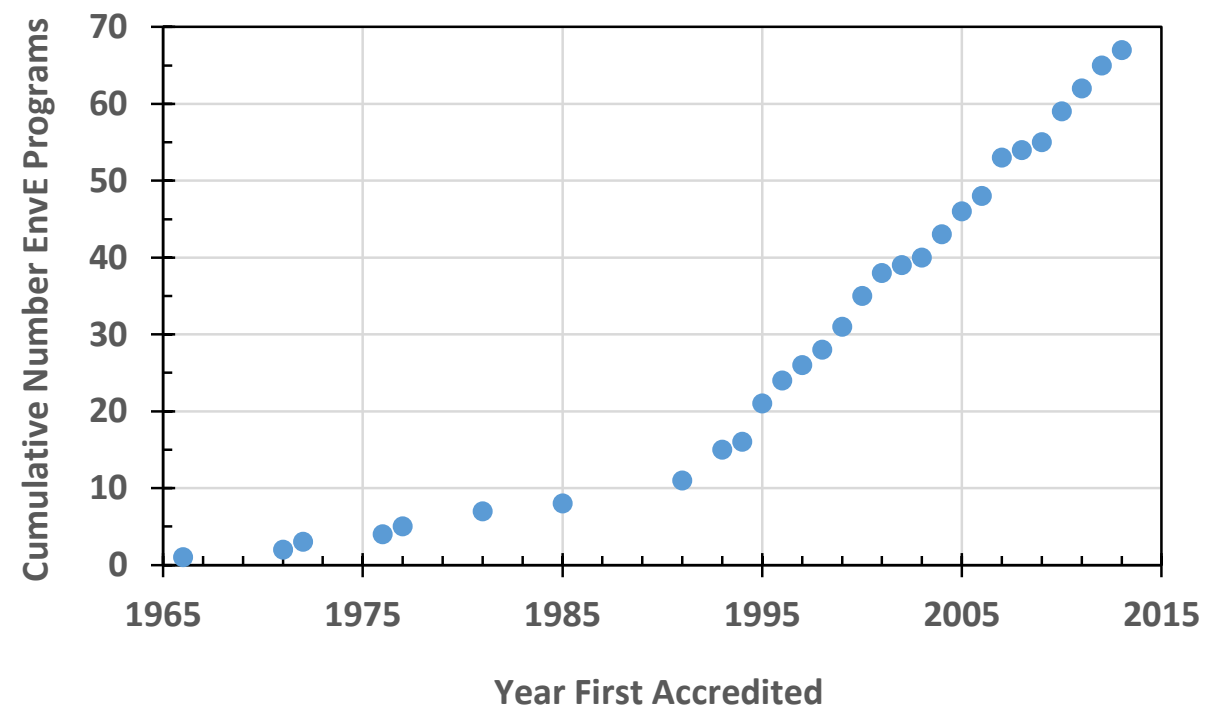

Figure 1. Growth in Number of ABET EAC-accredited EnvE programs in the U.S.

The Environmental Engineering Body of Knowledge (BOK) outlined aspirational content for bachelor's degree programs in environmental engineering. It acknowledged the historical roots of the environmental engineering discipline, stating “in the1980's and 1990's, environmental engineering evolved into a stand-alone engineering discipline...engineers came to view this discipline as separate from, albeit related to, allied engineering disciplines such as civil and chemical engineering." (p. 7). The BOK also recognized that a balance of technical and nontechnical abilities is important; "the environmental engineer practicing at full professional capacity should have the technical breadth to relate to engineers and specialists from other disciplines as well as the non-technical breadth to positively influence society and stakeholders." (p. 20) Expanding on the importance of non-technical competencies, humanities 
and social sciences was among the 16 knowledge domains explicitly articulated in the EnvE BOK. This knowledge domain was mapped to 10 of the 18 BOK outcomes: 6 - problem formulation and conceptual analysis, 7 - creative design, 10 societal impact, 11 - contemporary and global issues, 13 - professional and ethical responsibilities, 14 - effective communication, 15 - lifelong learning, 16 - project management, 17 - business and public administration, and 18 leadership.

Given the background related to individuals' needs for autonomy and the importance that engineers possess both technical and non-technical skills, the following research questions motivated this study:

(1) To what extent do top-ranked environmental engineering programs allow students to make choices in their courses (such as free electives and technical electives)?

a. How do choice opportunities in EnvE compare to chemical and civil engineering degrees?

b. How do choice opportunities in EnvE compare to non-engineering degrees in chemistry, math, and physics?

(2) What is the balance of required technical and non-technical courses in top-ranked environmental engineering curricula?

a. How does the curricular balance in EnvE compare to chemical and civil engineering degrees?

b. How do the technical course requirements in EnvE compare to non-engineering degrees in chemistry, math, and physics?

The answers to these questions will form a picture of the state of choice and curricular balance in environmental engineering, and might help others to consider modifications to their programs to embrace concepts from self-determination theory and considering the diverse career pathways of environmental engineering graduates.

\section{Methods}

It was desired to benchmark the choice and curricular balance in top ranked environmental engineering degree programs. The US News \& World Report specialty rankings for environmental/environmental health in 2015 were consulted $;{ }^{10}$ this included 17 programs at doctoral institutions among the top 20 list. However, only 10 of these schools offered environmental engineering degrees; many of those without environmental engineering degrees offered "civil and environmental" engineering degrees but these were typically accredited under the civil engineering criteria. The U.S. News \& World Report ranks undergraduate engineering programs and specialty engineering programs based solely on assessment surveys of engineering deans and senior faculty members, noting "Schools offering any courses in a specialty are eligible to be ranked in that specialty area. The specialty rankings are not based on whether an engineering program has specific undergraduate-level ABET accreditation in that specialty area." 11

In order to expand the pool of environmental engineering programs being explored, environmental engineering degrees from institutions where the overall engineering program was ranked in the top-20 lists for doctoral and non-doctoral institutions from US News \& World 
report were included. Once the ability to locate on-line catalog information was verified, that left 19 EnvE programs in the top-ranked group. Ten of the programs were at public institutions and nine were at private institutions. The characteristics of these institutions are shown in Table 1 (compared to institutional characteristics among all ABET-accredited environmental engineering programs). In general, the top-ranked programs were over-represented in RU/VH (research universities with very high research activity) institutions, ${ }^{18}$ had fewer small programs, and were over-represented for institutions offering a large number of different accredited engineering specialty degrees. Of the programs, eight were first accredited in 2000-2013; five were accredited in 1999 or earlier; six of the programs were not accredited (although one would have been accredited in 2013, at the time the catalog was benchmarked).

Table 1: Institution data for top-ranked and all environmental engineering programs.

\begin{tabular}{|c|c|c|c|c|c|c|c|c|}
\hline $\begin{array}{c}\text { Institution } \\
\text { Type }^{\mathbf{1 8}}\end{array}$ & $\begin{array}{c}\text { All ABET } \\
\text { EnvE } \\
\text { Progs. }\end{array}$ & $\begin{array}{c}\text { N of } \\
\mathbf{1 9} \text { in } \\
\text { this } \\
\text { study }\end{array}$ & $\begin{array}{c}\text { Total } \\
\text { Enrollment } \\
\text { Size }\end{array}$ & $\begin{array}{c}\text { All } \\
\text { ABET } \\
\text { EnvE } \\
\text { Progs. }\end{array}$ & $\begin{array}{c}\text { Nof } \\
\mathbf{1 9} \text { in } \\
\text { inis } \\
\text { study } \\
\text { accredited } \\
\text { Engineering } \\
\text { Degree } \\
\text { Programs at } \\
\text { University }\end{array}$ & $\begin{array}{c}\text { All ABET } \\
\text { EnvE } \\
\text { Progs. }\end{array}$ & $\begin{array}{c}\text { N of 19 } \\
\text { in this } \\
\text { study }\end{array}$ \\
\hline Bachelor's & 3 & 1 & Small, <5000 & 10 & 1 & $1-3$ & 7 & 2 \\
\hline Master's & 11 & 2 & Medium, 5-15K & 18 & 8 & $4-6$ & 11 & 3 \\
\hline DRU & 4 & 0 & Large, $>15 \mathrm{~K}$ & 39 & 10 & $7-9$ & 23 & 3 \\
\hline RU/H & 19 & 0 & & & & $10-12$ & 18 & 6 \\
\hline RU/VH & 30 & 16 & & & & $13-18$ & 8 & 5 \\
\hline
\end{tabular}

For each of the 19 degree programs, course choice opportunity data were gathered from the 2013-2014 online university catalog. As a continuation of a previous study on course choice opportunity in engineering, ${ }^{3,4}$ this work utilized three course choice variable metrics for a multidimensional delineation of course choice opportunity within each studied degree program, including: Total Free Elective Credit Hours ("free electives"), Total Choice Count ("total choice"), and Weighted Choice Score ("weighted choice").

The universities included in this study had varied methods of quantifying the courses that students take as part of their degree programs. For example, one university required a total of 32 courses for their Bachelors of Science degree in environmental engineering, where each course counted for one of the 32 course requirement; credit hours were not used as part of their system. Other universities used quarter $(n=4)$ and semester $(n=15)$ methods, and had a wide range of credit hour requirements all the way up to the 190 credit hours. Due to these varied metrics, in all cases, course choice opportunity data were normalized to 128 total degree credit hours (the median among the total required credits for the 19 environmental engineering degree programs). For example, a 3 credit hour free elective course choice opportunity as part of a 120 degree program would be normalized to 3.2 credit hours in a 128 credit hour degree program as follows: $3 *(128 / 120)=3.2$. The same credit hour normalization method was used throughout this study.

Total Free Elective Credit Hours represent the sum of all credit hours out of the 128 credit hour total for which students are free to choose any course. No restrictions are placed on these course selections. 
Total Choice Count is the sum of all credit hours out of the 128 credit hour total for which students get to make some kind of choice in the course they take. These choices could include free electives, technical electives, humanities electives, etc., or simply getting to pick a writing class out of two options.

Weighted Choice Score adds a dimension of magnitude to total choice. To calculate the weighted choice for a given degree program, the course choice opportunity credit hours for the program were categorized as either: 1 . courses chosen from a list of options (such as multiple options for a statistics or earth science lab course), 2. courses chosen from one department, 3. Courses chosen from more than one department, or 4 . free electives (Table 2).

Table 2. Weighted Choice Score course choice opportunity categories and weights.

\begin{tabular}{|c|l|l|c|c|}
\hline Category & \multicolumn{1}{|c|}{ Definition } & \multicolumn{1}{|c|}{ Examples } & Weight & $\begin{array}{c}\text { Weight } \\
\text { Fraction }\end{array}$ \\
\hline 1 & $\begin{array}{l}\text { Courses chosen from a list of } \\
\text { options. }\end{array}$ & $\begin{array}{l}\text { "Choose 2 of the following 4 courses" } \\
\text { "Choose one course from the } \\
\text { following list of options" }\end{array}$ & 3 & 0.0023 \\
\hline 2 & $\begin{array}{l}\text { Courses chosen from one } \\
\text { department } \text { or } \text { engineering electives. }\end{array}$ & $\begin{array}{l}\text { "Physics elective," "History elective," } \\
\text { "Mechanical Engineering elective" }\end{array}$ & 22 & 0.0170 \\
\hline 3 & $\begin{array}{l}\text { Course choices outside of } \\
\text { engineering, chosen from more than } \\
\text { one department (but not a free } \\
\text { elective) }\end{array}$ & $\begin{array}{l}\text { "social sciences elective," "humanities } \\
\text { elective", "technical elective" }\end{array}$ & 88 & 0.0681 \\
\hline 4 & Free electives. & $\begin{array}{l}\text { These course choice opportunities } \\
\text { have no restrictions. }\end{array}$ & 1292 & 1 \\
\hline
\end{tabular}

The weights for each matrix category were designed to capture the magnitude of choice for each type of course choice opportunity. The weighted values originated from a five-university pilot study $^{3}$ wherein the actual numbers of courses students got to pick from for each course choice opportunity were counted; the weights for each category in Table 2 were the median course count values from the pilot study. These weights were then normalized to the weight of the free elective category to produce a weighted fraction. From the counts and the category weights, the Weighted Choice Score (WCS) for a program was calculated:

$$
W C S=\Sigma \text { (number of credits in category * weighted fraction for the category) }
$$

Comparators. The data for the choice metrics gains more relevance when it is contextualized against other engineering degree programs and non-engineering degrees. Forbes ${ }^{4}$ previously calculated the choice metrics for top-ranked chemical and civil engineering degree programs; environmental engineering often shares roots in these disciplines and therefore these degree programs will be used as comparators. Further, Forbes ${ }^{4}$ computed choice metrics for the median of all engineering specialty degrees at the top-ranked doctoral and non-doctoral institutions; these values also provide a basis for comparison. Finally, Forbes ${ }^{4}$ computed choice metrics for five non-engineering degrees at institutions with the top-ranked engineering programs. For each institution the median choice across math, chemistry, physics, economics, and psychology were computed. 
Microsoft Excel 2013 was used for data collection and calculations of university choice variable data for this study. Statistical analyses were performed using SPSS and MVPstats. Because the data were ordinal based on counts, non-parametric statistics were used. Mann-Whitney U tests were used to detect statistically significant differences between two independent samples of ordinal data and the Spearman Rank Correlation statistical test was used to test for coefficients of association between ordinal variables. In all cases tests were two-tailed, with significance levels of $\alpha=0.05$.

Box-and-whisker plots will be used to visualize the data; these show the median (the center of the box), the first quartile (Q1, lower, darker shaded extent of the box), third quartile (Q3, upper, light gray extent of the box), and maximum (upper extent of whisker) and minimum (lower extent of whisker); statistical outliers are also shown and may extend beyond the whiskers.

\section{Results and Discussion}

\section{Choice in environmental engineering programs}

First, it was found that the majority of the environmental engineering programs in this study afforded very few free elective opportunities to students (Figure 2). Ten of the 19 programs allowed no free elective credits, resulting in a median of zero free electives (thus no lower part of the box-plot visible in Figure 2). There were three programs that allowed 2.0-3.8 credits of free electives (1.6-3.0\% of the curriculum), as well as 5 programs that allowed 11.3 to 16 credits of free electives (8.8-12.5\%; including 3 accredited programs) and 1 that allowed 28.4 credits of free electives (this program is not accredited). The results indicate that a few programs allow students flexibility to avail themselves of any course of their choosing. Free electives in a curriculum could be particularly beneficial for allowing student in-migration from nonengineering disciplines and allowing those students a chance at on-time graduation.

Within the total choice count, a wide range of choice is evident, ranging from 22 to $80 \%$ of the curriculum (median of $44 \%$ or 56 credits, see Figure 2). In all cases, a significant portion of this choice lies within technical coursework - ranging from $22-75 \%$. The technical coursework requirements with choice ranged from 7.5 to 76.6 credits (6-60\% of the overall curriculum). In some cases these choices are very minor, such as a choice between two different chemistry courses. In other cases these are wider "technical electives" that encompass a very broad range of options across any engineering and many natural science disciplines.

The weighted choice scores also show significant variability across the 19 environmental engineering degree programs (Figure 2). Given the weighting of the various course choice categories, in programs with free electives those courses determined the majority of the weighted choice score. Thus, the six programs with the highest percentage of free electives also had the six highest weighted choice scores. However, the contribution of additional choice types is also evident. Three programs had very low weighted choice scores, which ranged from 0.20 to 0.80 . 

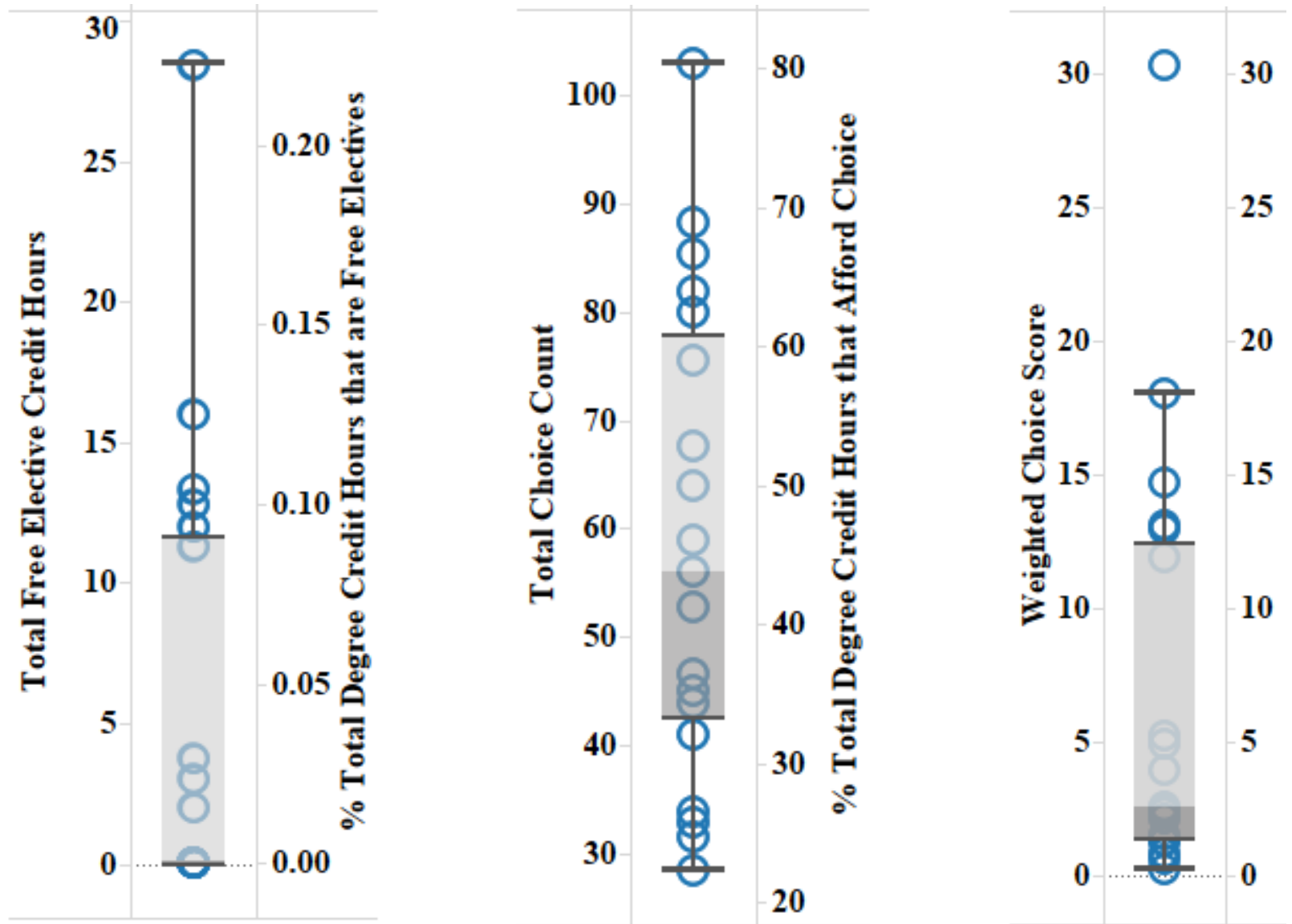

Figure 2. Free elective, total, and weighted course choice opportunity for 19 environmental engineering programs, with overlay of box-and-whisker plot to reflect Q1, median, and Q3.

\section{Choice comparisons between institution types}

Some institution types had significant differences in the amount of choice in their environmental engineering curricula (Table 3). The private institutions had more total choice credits and higher Weighted Choice Scores than public institutions. Programs at medium and small institutions had somewhat more weighted choice as compared to large institutions. There were not significant choice differences between EAC and non-EAC accredited EnvE programs.

Table 3. Comparison of median choice metrics for environmental engineering programs at different types of institutions

\begin{tabular}{|l|c|c|c|}
\hline \multicolumn{1}{|c|}{ Institution Type } & $\begin{array}{c}\text { Median } \\
\text { Free Elective } \\
\text { Credits }\end{array}$ & $\begin{array}{c}\text { Median } \\
\text { Total Choice } \\
\text { Credits }\end{array}$ & $\begin{array}{c}\text { Median } \\
\text { Weighted } \\
\text { Choice }\end{array}$ \\
\hline Not Accredited $(\mathrm{n}=6)$ & 7.5 & 73 & 8.5 \\
Accredited $(\mathrm{n}=13)$ & 0.281 & 53.487 & 2.4 .210 \\
\hline Private $(\mathrm{n}=9)$ & 3.8 & 75 & 5.2 \\
Public $(\mathrm{n}=10)$ & 0.315 & $45^{.010}$ & 1.4 .043 \\
\hline Large $(\mathrm{n}=10)$ & 0 & 46 & 1.9 \\
Medium+Small $(\mathrm{n}=9)$ & 3.8 .315 & 68.278 & 5.2 .095 \\
\hline
\end{tabular}

Superscript $=$ Independent-samples Mann Whitney U Test sig. 
The impact of institution size was confirmed by correlation analysis (Table 4), which found weighted choice weakly negatively correlated with the undergraduate population at the institution; this indicates that EnvE programs at larger institutions tend to offer fewer overall weighted choice opportunities to environmental engineering students. This represents a combination of fewer choices and/or lower flexibility choices. No other correlations between choice metrics and quantitative institution characteristics were found.

Table 4. Spearman's rho correlation values for environmental engineering program choice metrics and institutional characteristics

\begin{tabular}{|l|c|c|c|}
\hline Choice Metric & $\begin{array}{c}\text { Undergraduate } \\
\text { Population }\end{array}$ & $\begin{array}{c}\text { Undergraduate } \\
\text { Engineering } \\
\text { Population }\end{array}$ & $\begin{array}{c}\text { \# Eng Specialty } \\
\text { Degrees Accred }\end{array}$ \\
\hline Free electives & $-0.293^{.223}$ & $-0.260^{.283}$ & $0.163^{.504}$ \\
\hline Total choice & $-0.356^{.135}$ & $-0.102^{.679}$ & $-0.114^{.643}$ \\
\hline Weighted choice & $-0.404^{.087}$ & $-0.388^{.101}$ & $0.002^{.994}$ \\
\hline
\end{tabular}

Superscripts are the sig. (2-tailed)

\section{Choice comparisons between environmental engineering and other majors}

Environmental engineering students had few choices, similar to other engineering majors and lower than non-engineering comparators (previously calculated ${ }^{4}$ ). As shown in Table 5, the median values for environmental engineering degrees for each of the three choice metrics was in the range of the medians for top-ranked chemical and civil engineering degree programs, as well as engineering majors at top ranked institutions in general (see Appendix A for corresponding figures). The results indicate that students are unlikely to be impacted in their type of engineering major based on choice disparity. In contrast, students may be unlikely to enter engineering from non-engineering majors due to its restrictiveness on course choices, and may be lured into other disciplines due to greater choice opportunities (Table 6). For example, chemistry programs at institutions with top-ranked engineering programs offered a median of 22 free elective credits (17\% of the requirements). This greater choice in non-engineering disciplines is complemented by fewer overall required credits to graduate - for example, a median of 124 credits for chemistry (overall; 124 credits for chemistry B.S. and 120 credits for chemistry B.A., 124 credits for math B.S. and 120 credits for math B.A., 126 credits for physics B.S. and 120 credits for a physics B.A.). Thus, a college experience that offers both choice and on-time graduation is perhaps more achievable via a switch out of environmental engineering into a related discipline. 
Table 5. Comparison of median choice metrics for different degree programs.

\begin{tabular}{|c|c|c|c|c|c|}
\hline $\begin{array}{c}\text { Choice } \\
\text { Variable }\end{array}$ & $\begin{array}{c}\text { EnvE } \\
(n=19)\end{array}$ & $\begin{array}{c}\text { Chemical } \\
(n=22)\end{array}$ & $\begin{array}{c}\text { Civil } \\
(n=19)\end{array}$ & $\begin{array}{c}\text { All Eng } \\
(\mathrm{n}=38)\end{array}$ & Non-engineering* \\
\hline $\begin{array}{r}\text { Total Free } \\
\text { Elective } \\
\text { Credit } \\
\text { Hours }\end{array}$ & $\tilde{x}_{\mathrm{Env}}=0.0$ & $\tilde{x}_{\text {Chem }}=0.0$ & $\tilde{x}_{\text {Civil }}=0.7$ & $\tilde{x}_{\mathrm{ENG}}=3.6$ & $\begin{array}{c}\tilde{x}_{\text {Non-Eng }}=30.9 \\
\tilde{x}_{\text {physics }}=20 \\
\tilde{x} \\
\tilde{x}_{\text {mathistry }}=22 \\
x_{\text {math }}\end{array}$ \\
\hline $\begin{array}{r}\text { Total } \\
\text { Choice } \\
\text { Count }\end{array}$ & $\tilde{x}_{\mathrm{Env}}=56.0$ & $\tilde{x}_{\text {Chem }}=43.9$ & $\tilde{x}_{\text {Civil }}=64.0$ & $\tilde{x}_{\mathrm{ENG}}=50.8$ & $\begin{array}{c}\tilde{x}_{\text {Non-Eng }}=96.0 \\
\tilde{x}_{\text {physics }}=81 \\
\tilde{x}_{\text {chemistry }}=77 \\
\tilde{x}_{\text {math }}=97\end{array}$ \\
\hline $\begin{array}{r}\text { Weighted } \\
\text { Choice } \\
\text { Score }\end{array}$ & $\tilde{x}_{\mathrm{Env}}=2.6$ & $\tilde{x}_{\text {Chem }}=1.9$ & $\tilde{x}_{\text {Civil }}=2.4$ & $\tilde{x}_{\mathrm{ENG}}=4.5$ & $\begin{array}{c}\tilde{x}_{\text {Non-Eng }}=32.9 \\
\widetilde{x}_{\text {physics }}=21 \\
\tilde{x}_{\text {chemistry }}=24 \\
\tilde{x}_{\text {math }}=32\end{array}$ \\
\hline
\end{tabular}

Table 6. Mann Whitney-U p-values (2-tailed significance) for 19 environmental engineering program choice metrics versus choice metrics for different programs from Table 5.

\begin{tabular}{|r|c|c|c|c|}
\hline Choice Metric & $\begin{array}{c}\text { EnvE v. } \\
\text { Chemical }\end{array}$ & $\begin{array}{c}\text { EnvE v. } \\
\text { Civil }\end{array}$ & $\begin{array}{c}\text { EnvE v. } \\
\text { All Eng }\end{array}$ & $\begin{array}{c}\text { EnvE v. } \\
\text { Phys, Chem, Math }\end{array}$ \\
\hline Free electives & 0.375 & 0.906 & 0.747 & 0.000 \\
\hline Total choice & 0.323 & 0.342 & 0.559 & 0.000 \\
\hline Weighted choice & 0.507 & 0.949 & 0.839 & 0.000 \\
\hline
\end{tabular}

\section{High Choice Exceptions}

Among the 19 environmental engineering programs, the four with the highest scores in each choice category were identified as "high choice exceptions" (HCEs; shaded yellow in Table 7). This resulted in the identification of seven HCE programs, since six of the programs were high choice exceptions across multiple choice metrics. Three of the HCE programs were not ABETaccredited, $71 \%$ were at private institutions, and $57 \%$ were small or medium sized institutions. There were a couple of distinct patterns apparent. Schools that were consistently high in all three choice metrics were A, B, and F. Schools C and G had fairly low total choice but relatively high free electives; thus a large percentage of the choice given to students was in the form of free electives (24-27\%). Schools D and E gave students a lot of very small "menu-type" choices and but no free electives, resulting in average weighted choice scores. The results indicate that there are curricular designs that can achieve ABET accreditation and high rankings while also allowing students to exercise their need for autonomy by choosing some of their courses. Of note, in a previous study universities A, B, C, and E we also identified as providing exceptionally high course choice opportunities to students across all engineering programs in the college. ${ }^{4}$ For these universities, the exceptional course choice opportunities in environmental engineering are perhaps reflections of overall institutional philosophies that lent themselves to more choiceoriented engineering programs in all disciplines. 
Table 7. Choice metrics from high choice exception (HCE) environmental engineering degree programs

\begin{tabular}{|c|l|c|c|c|c|}
\hline Institution & Characteristics & $\begin{array}{c}\text { EnvE. } \\
\text { Rank }\end{array}$ & $\begin{array}{c}\text { Free } \\
\text { Electives }\end{array}$ & $\begin{array}{c}\text { Total } \\
\text { Choice }\end{array}$ & $\begin{array}{c}\text { Weighted } \\
\text { Choice }\end{array}$ \\
\hline A & Private, medium & NR & 28.4 & 82 & 30.3 \\
\hline B & Private, medium, ABET & Top 10 & 16 & 80 & 18.0 \\
\hline C & Private, medium, ABET & NR & 13.3 & 56 & 14.7 \\
\hline D & Private, large, ABET & Top 20 & 0 & 103 & 2.6 \\
\hline E & Private, medium & Top 10 & 0 & 88 & 2.3 \\
\hline F & Public, large & NR & 12.8 & 85 & 13.0 \\
\hline G & Public, large, ABET & Top 10 & 12.0 & 45 & 13.1 \\
\hline \multicolumn{7}{r|}{ Median of 7 HCE programs } & $\mathbf{1 2 . 8}$ & $\mathbf{8 2}$ & $\mathbf{1 3 . 1}$ \\
\hline \multicolumn{7}{r|}{ Median of All 19 EnvE programs } & $\mathbf{0}$ & $\mathbf{5 6}$ & $\mathbf{2 . 6}$ \\
\hline
\end{tabular}

$\mathrm{NR}=$ environmental engineering program not ranked in top 20; engineering undergraduate program as a whole ranked in the top 20

\section{Curricular Balance}

Beyond the issue of choice for students, it was of interest to explore the balance between technical (engineering, math, natural science) and non-technical coursework. In the environmental engineering degree programs (Figure 3), there was a median of $42 \%$ required engineering coursework, $78 \%$ required technical coursework, $18 \%$ non-technical coursework, and $23 \%$ possible non-technical coursework (free + required non-technical). The minimum requirement for technical coursework under ABET EAC accreditation is 2.5-years of a 4-year curriculum or $62.5 \%$ of the coursework; for the median 128-credit environmental engineering degree in this study, that represents 80 credit hours. One of the non-accredited programs was below this level of technical content at 55.6\% (71 credits); this program will be discussed further below. For required non-technical coursework, this median represents about one 3-credit nontechnical course per semester and slightly over four 3 -credit technical courses per semester. 


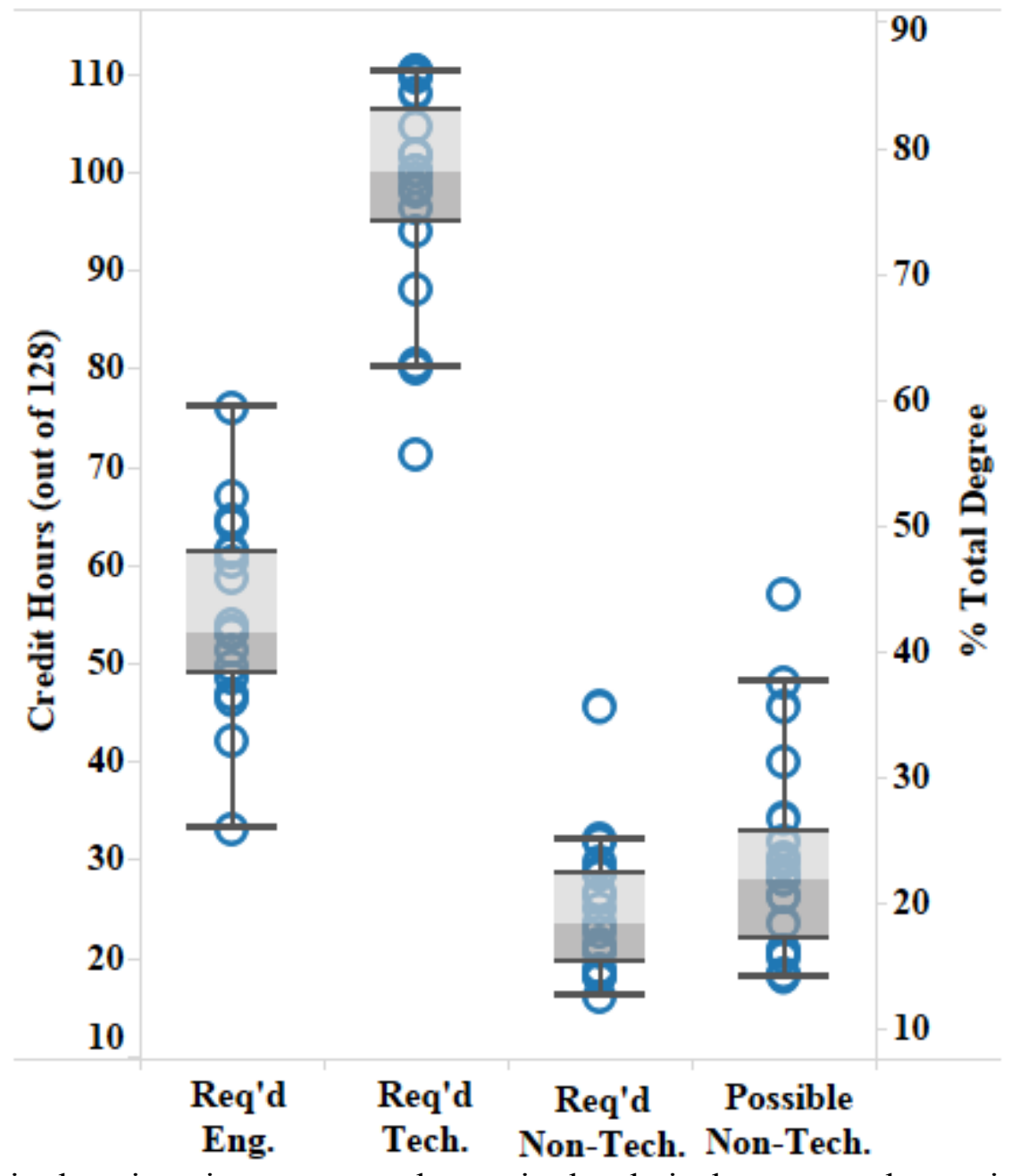

Figure 3. Required engineering coursework, required technical coursework, required nontechnical coursework, and possible non-technical coursework (free electives + required nontechnical coursework) for 19 environmental engineering programs.

The technical - non-technical balance in environmental engineering programs is similar to other engineering disciplines but far lower than non-engineering STEM peers at the institutions with top-ranked engineering programs (Table 8). At worst, the ratio of required non-technical coursework to technical coursework in environmental engineering was 0.16 (16.0 credits required non-technical / 100.0 credits required technical), while at best it was 0.57 ( 45.5 credits required non-technical / 80.4 credits required technical) (median 0.23). By comparison, for chemistry degrees, the ratios ranged from 0.25 (24.9 credits required non-technical / 100.3 credits required technical) to 1.33 ( 41.3 credits required non-technical / 31.0 credits required technical; this program was a B.A.), with a median of 0.44 . 
Table 8. Median credit hours of different types of coursework in the curriculum

\begin{tabular}{|c|c|c|c|c|c|}
\hline $\begin{array}{c}\text { Course } \\
\text { Type }\end{array}$ & $\begin{array}{c}\text { Environmental } \\
(\mathbf{n = 1 9 )}\end{array}$ & $\begin{array}{c}\text { Chemical } \\
(\mathbf{n = 2 2})\end{array}$ & $\begin{array}{c}\text { Civil } \\
(\mathbf{n = 1 9 )}\end{array}$ & $\begin{array}{c}\text { All Eng } \\
(\mathbf{n = 3 8})\end{array}$ & STM Degrees* $^{*}$ \\
\hline Technical & 100.0 & 101.0 .786 & 100.0 .568 & 98.2 .137 & $\begin{array}{c}\text { Chem } 67.8^{.000} \\
\text { Math } 58.9^{.000} \\
\text { Physics } 70.4 .000\end{array}$ \\
\hline $\begin{array}{c}\text { Non- } \\
\text { technical }\end{array}$ & 23.5 & 24.5 .828 & 25.6 .392 & 26.4 .162 & $\begin{array}{c}\text { Chem 32.0.000 } \\
\text { Math 37.1.000 } \\
\text { Physics 34.6.000 }\end{array}$ \\
\hline $\begin{array}{c}\text { Possible } \\
\text { non- } \\
\text { technical }\end{array}$ & 28.0 & 27.0 .684 & 28.0 .568 & 29.8 .145 & $\begin{array}{c}\text { Chem 58.9.000 } \\
\text { Math } 69.12 .000 \\
\text { Physics 57.6.000 }\end{array}$ \\
\hline
\end{tabular}

${ }^{*}$ Chemistry $\mathrm{n}=49 ;$ Math $\mathrm{n}=56$; Physics $\mathrm{n}=56$

Superscripts are the Mann-Whitney U sig. (2-tailed) for comparison with the 19 EnvE programs.

Between institution types (small-medium vs. large, private vs. public, and accredited vs. nonaccredited) there were not significant differences in the percentage of the curriculum that was required technical coursework, non-technical coursework, or possible non-technical (MannWhitney U test, sig. all 0.133 or more); Table 9. However, the private institutions had somewhat lower technical requirements and allowed higher possible non-technical coursework as compared to public institutions.

Table 9. Institution types and median percentage of course types in the environmental engineering curriculum.

\begin{tabular}{|l|c|c|c|}
\hline \multicolumn{1}{|c|}{ Institution Type } & $\begin{array}{c}\text { \% required } \\
\text { technical }\end{array}$ & $\begin{array}{c}\text { \% required } \\
\text { non-technical }\end{array}$ & $\begin{array}{c}\text { \% possible } \\
\text { non-technical }\end{array}$ \\
\hline Large $(\mathrm{n}=10)$ & 79 & 17 & 17 \\
Medium+Small $(\mathrm{n}=9)$ & 76.156 & 21.278 & 24.133 \\
\hline Private $(\mathrm{n}=9)$ & 76 & 21 & 24 \\
Public $(\mathrm{n}=10)$ & 80.065 & 16.133 & 16.095 \\
\hline Not Accredited $(\mathrm{n}=6)$ & 75 & 17 & 23 \\
EAC Accredited $(\mathrm{n}=13)$ & 78.244 & 20.898 & 22.152 \\
\hline
\end{tabular}

Superscripts are the sig. (2-tailed)

Exceptional environmental engineering programs that offered students more balance were identified (Table 10). These five "high non-technical exception" (HNTE) programs included the three with the lowest required technical coursework, the three with the highest non-technical coursework required, and the three with the highest possible non-technical coursework. Of the five HNTE programs, four were at private, medium sized institutions. Institution A would fail to meet ABET requirements, which specify 1-year of math and natural sciences and 1.5 years of technical coursework, which is a total of 2.5 / 4 years or $63 \%$. As shown by comparing institution $\mathrm{B}$, it is possible to accredit a program with the minimal amount of required technical content. 
Table 10. Environmental engineering programs with high non-technical balance.

\begin{tabular}{|c|l|c|c|c|}
\hline \multirow{2}{*}{ Institution } & Characteristics & $\begin{array}{c}\text { \% required } \\
\text { technical } \\
\text { courses }\end{array}$ & $\begin{array}{c}\text { \% required } \\
\text { non-technical } \\
\text { courses }\end{array}$ & $\begin{array}{c}\text { Maximum \% } \\
\text { possible non- } \\
\text { technical } \\
\text { courses }\end{array}$ \\
\hline A & Private, medium & 56 & 22 & 44 \\
E & Private, medium & 63 & 36 & 36 \\
B & Private, medium, ABET & 63 & 25 & 38 \\
C & Private, medium, ABET & 69 & 21 & 31 \\
H & Public, large, ABET & 75 & 25 & 25 \\
\hline \multicolumn{2}{|c|}{ Median of 5 HNT programs } & 63 & 25 & 36 \\
\hline \multicolumn{2}{|c|}{ Median of All 19 EnvE programs } & 78 & 18 & 22 \\
\hline
\end{tabular}

All five of the HNTE programs were also among the eight most flexible programs. This alludes to the fact that perhaps most of the choice frequently resides in the non-technical coursework. However, this was not found to be the case. The median percentage of the total choice that was due to technical course choice was $48 \%$ (range $22 \%$ to $75 \%$ ). Therefore, it rather appears that these environmental engineering programs have a curriculum development philosophy that embraces the importance of both non-technical coursework and choice. It is interesting that all five of the universities with HNTE environmental engineering programs were also identified in a previous study as providing exceptional course choice opportunities to students across all engineering programs in the college, ${ }^{4}$ perhaps an indication that these universities value both curricular choice and balance. Universities A, E, and B have also previously been found to have other engineering programs (including mechanical, electrical, and civil) with comparatively high non-technical requirements, ${ }^{4}$ again suggesting that the HNTE environmental engineering programs were influenced by institutional philosophies that value curricular balance and the nontechnical components of an undergraduate engineering education.

\section{Summary and Conclusions}

This study presented an opportunity to take stock of current environmental engineering curricular models to assess whether they can be improved to better align with students' innate psychological need for autonomy and the need for engineers to possess both technical and nontechnical skills. The results demonstrate that, like their engineering peers, environmental engineering curricula tend to offer little choice to their students as compared to non-engineering disciplines. Based on the studied population of programs, environmental engineering students are unlikely to be impacted in their type of engineering major based on choice disparity, but students may be unlikely to enter engineering from non-engineering majors due to its restrictiveness on course choices, and may be lured into other disciplines due to greater choice opportunities. The greater choice in non-engineering disciplines is complemented by fewer overall required credits to graduate. Thus, a college experience that offers both choice and on-time graduation is perhaps more achievable via a switch out of environmental engineering into a related discipline.

However, this minimal choice tendency in environmental engineering programs is not universally true. There are highly ranked, ABET-accredited environmental engineering programs that offer more choices to their students in terms of free electives, total course choice opportunities, and the magnitude of those opportunities. Though the majority of the 
environmental engineering programs in this study afforded very few free elective opportunities to students, for example, several exceptional programs offer considerable free elective opportunities. Free electives in a curriculum could be particularly beneficial for allowing student in-migration from non-engineering disciplines and allowing those students a chance at on-time graduation.

The results also demonstrate that the technical—non-technical balance in environmental engineering programs is similar to other engineering disciplines but far lower than nonengineering STEM peers at the institutions with top-ranked engineering programs. Again, this tendency is not universally true, and exceptional environmental engineering programs were identified that offered students a more balanced curriculum. Here again, free electives provide an avenue for students to customize the technical - non-technical balance of their degree program with the ability to devote their free elective credit hours to technical or non-technical pursuits, per their own interests. Free elective opportunities additionally make it more navigable for students to pursue minors, certificates, or study abroad opportunities.

Further research is needed to explore how environmental engineering students perceive the opportunity for choice and the balance of technical/non-technical courses in their programs. For example, some students prefer highly technical programs and disdain being forced to take what they view as "useless" humanities and social science courses. ${ }^{20}$ Some students seem to flounder when selecting their electives from broad ranges of options - such as fairly open technical electives or free electives. Other students appear to desire choice, and particularly value the opportunity to take advantage of the breadth of course opportunities available in college. Are environmental engineering students more similar to peers in engineering, environmental science, or environmental studies in their preferences for choice and non-technical coursework? Are there differences in the preferences for choice and non-technical coursework between students from different demographic groups (gender, race, socio-economic status, etc.)? Future qualitative studies may shed light on these questions.

Further research should also be conducted to query faculty about the philosophy that guided the design of the environmental engineering curricula. Were faculty designing the course requirements to prepare students to become professionally licensed environmental engineers in the future? If so, a constrained and technically-focused program may seem a necessity, in order to meet the Body of knowledge. ${ }^{9}$ Alternatively, if faculty view the Master's degree as a prerequisite for professional licensure, this may give them more flexibility in their Bachelor's degree programs. ${ }^{21}$ Another way to frame the discussion may be to consider the two cultures of engineering - one professional and one industrial. ${ }^{21}$ A very different mindset often drives curricular design in liberal arts, where they view college as an opportunity for exploration and personal growth rather than vocational training. The different educational approaches will bring different types of students into the workforce, but the extent to which students are aware that different options exist to earn an environmental engineering bachelor's degree is unknown.

The exceptional accredited and highly ranked environmental engineering programs that allow both choice and greater curricular balance serve as examples to others who may want to design their programs that allow students to exercise their innate need for autonomy and also balance their educational experience. Faculty should carefully consider these issues among other factors 
as they update and modify the curricular requirements in environmental programs at their institutions.

\section{References}

${ }^{1}$ Ryan, R. M., \& Deci, E. L. (2000). Self-Determination Theory and the Facilitation of Intrinsic Motivation, Social Development, and Well-Being. American Psychologist, 55(1), 68-78.

${ }^{2}$ Deci, E. L., Vallerand, R. J., Pelletier, L. G., \& Ryan, R. M. (1991). Motivation and Education: The SelfDetermination Perspective. Educational Psychologist, 26(3, 4), 325-346.

${ }^{3}$ Forbes, M.H., Bielefeldt, A.R., \& Sullivan, J.F. (2015). The Choice Opportunity Disparity: Exploring Curricular Choice Opportunities for Engineering vs. Non-Engineering Majors. Proceedings, ASEE Annual Conference \& Exposition, Seattle, WA, June.

${ }^{4}$ Forbes, M.H. (2015). Course choice opportunity and technical - non-technical balance in undergraduate engineering education. Ph.D. Dissertation, University of Colorado Boulder.

${ }^{5}$ The Accreditation Board of Engineering and Technology. Retrieved September 4, 2015. http://www.abet.org/accreditation/accreditation-criteria/criteria-for-accrediting-engineering-programs-20152016/

${ }^{6}$ The Accreditation Board of Engineering and Technology Program Search. Retrieved December, 2015. http://main.abet.org/aps/accreditedprogramsearch.aspx

${ }^{7}$ Stanford University, Environmental Engineering Program. Retrieved November 13, 2015. http://web.stanford.edu/group/ughb/cgi-bin/handbook/index.php/Environmental_Engineering_Program

${ }^{8}$ South Dakota School of Mines and Technology, Environmental Engineering Program. Retreived November 13, 2015. http://www.sdsmt.edu/Academics/Departments/Civil-and-Environmental-Engineering/UndergraduateEducation/

${ }^{9}$ American Academy of Environmental Engineers (AAEE). (2011). Environmental Engineering Body of Knowledge.

${ }^{10}$ US News \& World Report 2015-16. US News \& World Report, 2015.

${ }^{11}$ US News. Best Undergraduate Engineering Programs Methodology. Posted Sept. 8, 2015. http://www.usnews.com/education/best-colleges/articles/undergraduate-engineering-programsmethodologyAccessed Nov. 13, 2015.

${ }^{12}$ Stefanou, C. R., Perencevich, K. C., DiCintio, M., \& Turner, J. C. (2004). Supporting autonomy in the classroom: Ways teachers encourage student decision making and ownership. Educational Psychologist, 39(2), 97-110.

${ }^{13}$ Assor, A., Kaplan, H., \& Roth, G. (2002). Choice is good, but relevance is excellent: Autonomy-enhancing and suppressing teacher behaviours predicting students' engagement in schoolwork. British Journal of Educational Psychology, 72(2), 261-278.

${ }^{14}$ Jones, B. D. (2009). Motivating Students to Engage in Learning: The MUSIC Model of Academic Motivation. International Journal of Teaching and Learning in Higher Education, 21(2), 272-285.

${ }^{15}$ Jones, B. D., \& Wilkins, J. L. (2013). Testing the MUSIC Model of Academic Motivation through confirmatory factor analysis. Educational Psychology, 33(4), 482-503.

${ }^{16}$ Vanasupa, L., Stolk, J., \& Harding, T. (2010). Application of self-determination and self-regulation theories to course design: Planting the seeds for adaptive expertise. International Journal of Engineering Education, 26(4), 914.

${ }^{17}$ Vanasupa, L., Stolk, J., \& Herter, R. J. (2009). The Four Domain Development Diagram: A Guide for Holistic Design of Effective Learning Experiences for the Twenty-first Century Engineer. Journal of Engineering Education, 98(1), 67-81.

${ }^{18}$ The Carnegie Classification of Institutions of Higher Learning. Indiana University, Bloomington, IN. Retrieved January 24, 2015. http://carnegieclassifications.iu.edu/

${ }^{19}$ Bielefeldt, A.R. (2010). Evolution of a Sustainability Focused First-Year Environmental Engineering Course. Proceedings, ASEE Annual Conference \& Exposition, Louisville, KY, June.

${ }^{20}$ Bielefeldt, A.R. (2016). Infusing Macroethical Ideas into a Senior Engineering Course. Proceedings, ASEE Annual Conference \& Exposition, New Orleans, LA, June.

${ }^{21}$ Walker, H.W. (2012). Policy 465: Latest Struggle in the "Revolt of the Engineers". Journal of Professional Issues in Engineering Education and Practice, 138 (4), 283-288. 


\section{Appendix A: Comparison of median choice metrics for different degree programs.}

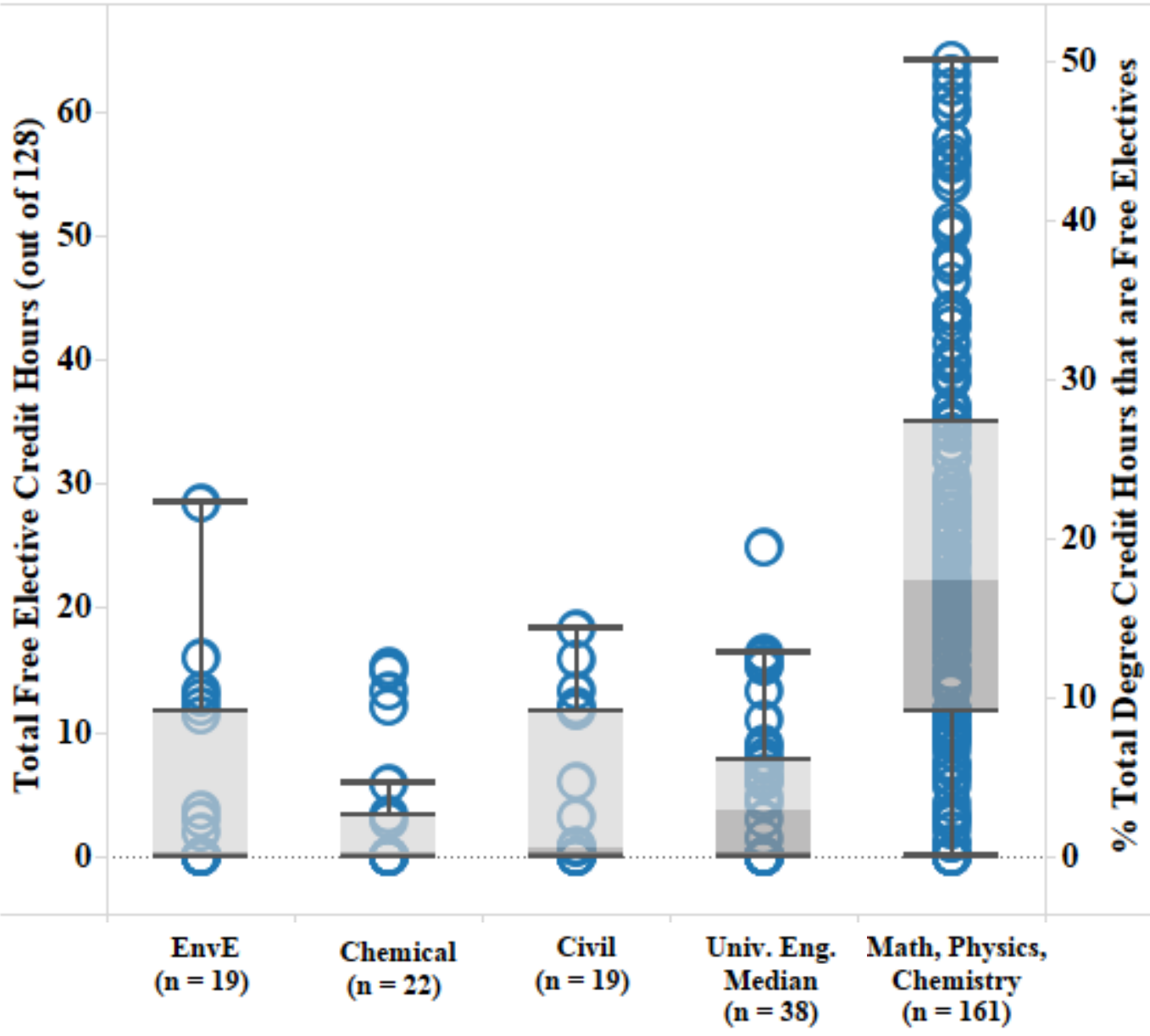

Note: Each "Univ. Eng. Median" value represents the median free elective credit hours across all engineering programs at a given university.

Figure A.1. Comparison of Total Free Elective Credit Hours for different degree programs. 


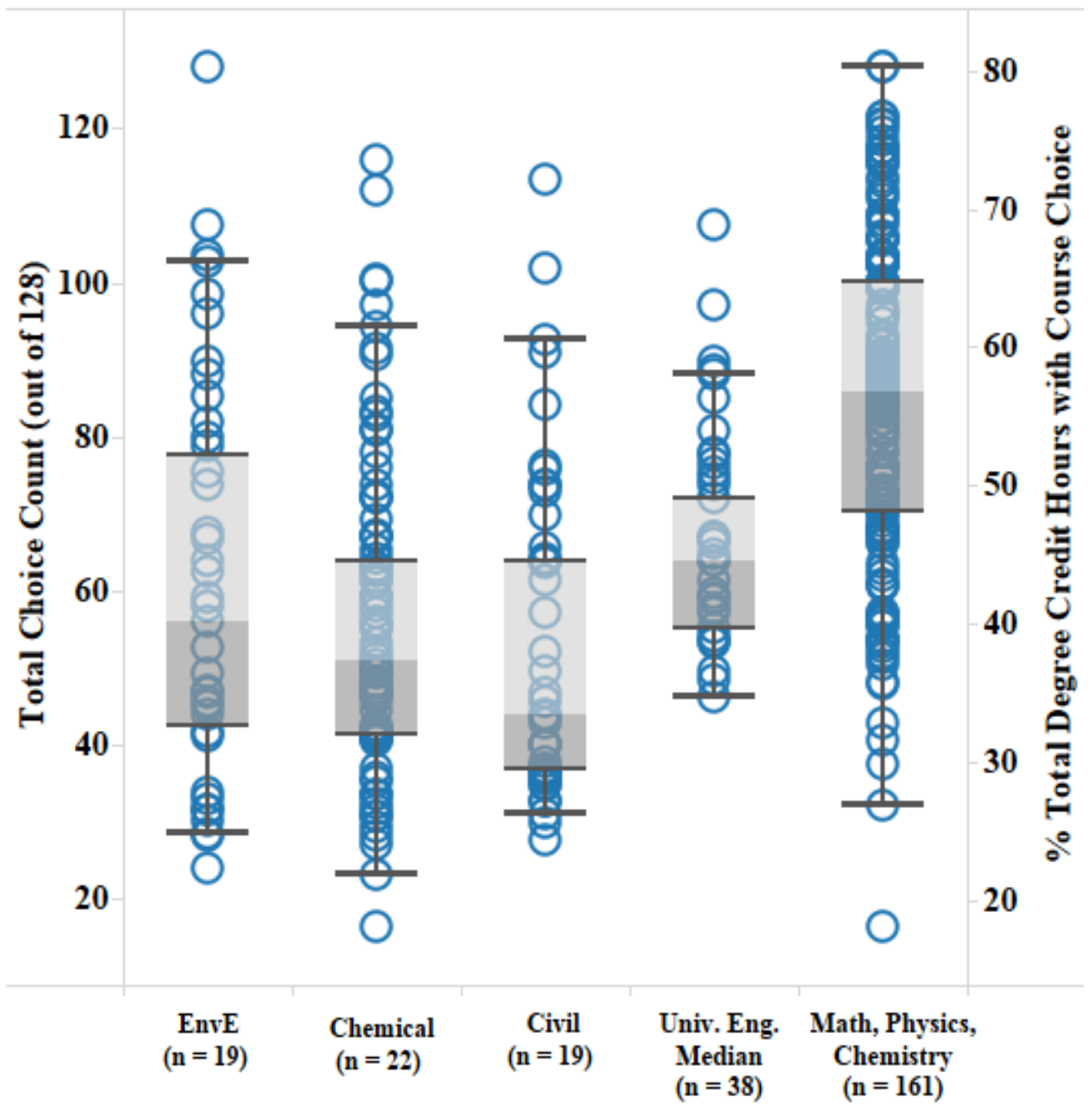

Note: Each "Univ. Eng. Median" value represents the median credit hours with choice across all engineering programs at a given university.

Figure A.2. Comparison of Total Choice Counts for different degree programs. 


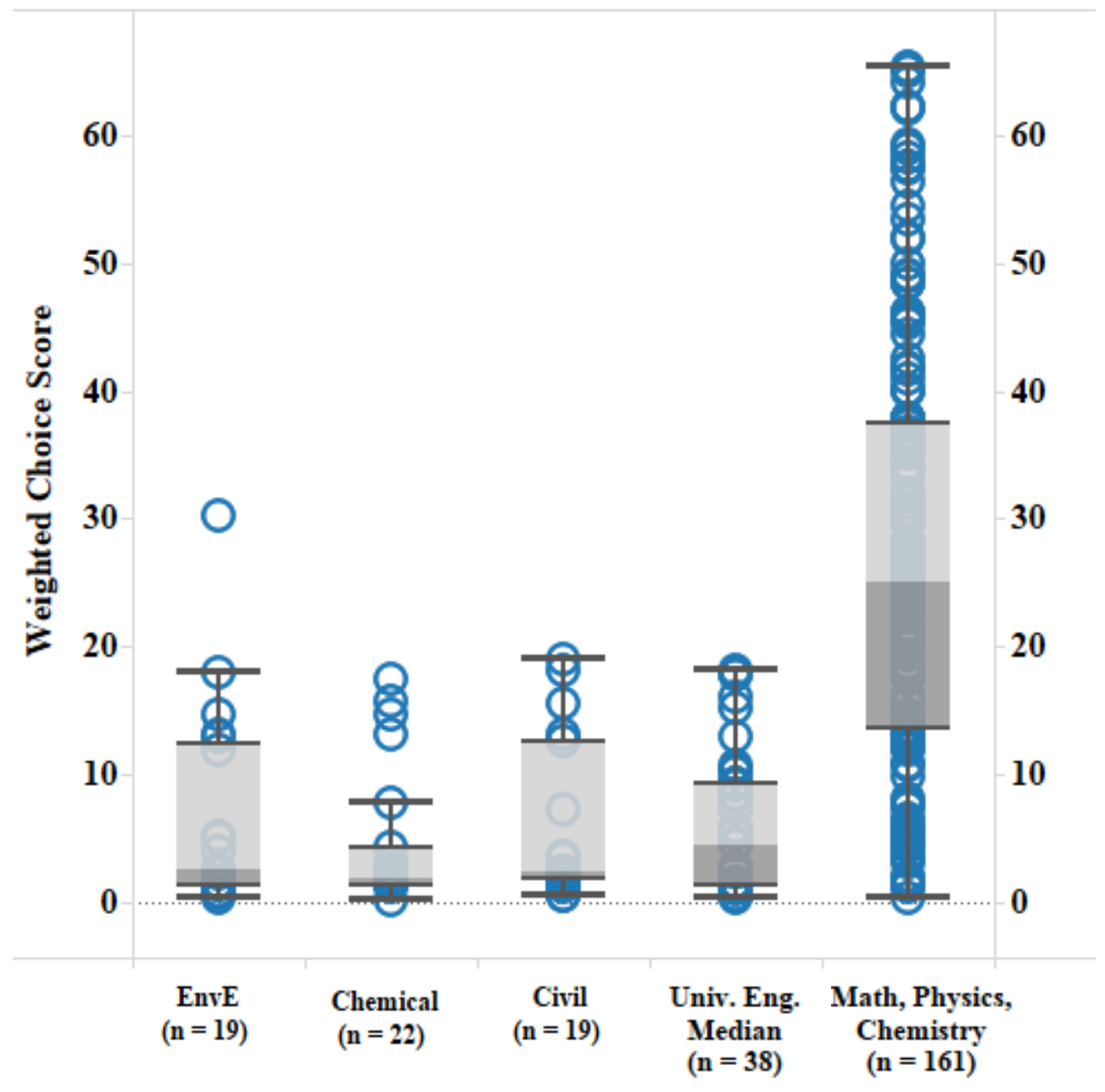

Note: Each "Univ. Eng. Median" value represents the median weighted choice score across all engineering programs at a given university.

Figure A.3. Comparison of Weighted Choice Scores for different degree programs. 